\title{
LA URBANIZACIÓN EN ARGENTINA DURANTE EL NEODESARROLLISMO. UNA LECTURA DESDE LAS RUPTURAS Y CONTINUIDADES CON EL PERÍODO NEOLIBERAL
}

\author{
THE URBANIZATION IN ARGENTINA DURING THE NEODEVELOPMENT PERIOD. A \\ REVIEW FROM DIFFERENCES AND SIMILARITIES WITH THE NEOLIBERALISM
}

\author{
Carolina Cisterna ${ }^{1}$ \\ Lucía Gisela Matteucci²
}

\section{Resumen}

Luego de la crisis del año 2001, la Argentina experimentó una fuerte recuperación económica que no se vio reflejada en las condiciones de acceso a la ciudad, en un contexto donde el mercado inmobiliario se ha transformado en un destino privilegiado de la inversión financiera. El objetivo principal de este trabajo es caracterizar el período actual de la historicidad urbana argentina -el neodesarrollista- en vínculo y relación con el neoliberal.

Metodológicamente dicha relación se abordó desde el análisis de tres nudos problemáticos: el mercado de suelo, la política urbana y el acceso a la ciudad. Para ello se utilizó información secundaria proveniente distintas fuentes como el Censo Nacional de Población, Hogares y Viviendas (2001 y 2010), distintos reportes inmobiliarios y páginas web de organismos estatales entre otros, y luego se hizo un análisis cualitativo de los datos.

En base a los datos trabajados podemos identificar que durante el neodesarrollismo se da una profundización del antagonismo entre mercantilización y acceso a la ciudad. Si bien el número de viviendas producidas aumentó, también lo hicieron el inquilinato, el hacinamiento y las ocupaciones con tenencia irregular o informal. El mercado inmobiliario expandió a niveles históricos su producción y como corolario de dicha expansión, el precio del suelo y de los inmuebles aumentó exponencialmente su valor, lo que implicó un mayor esfuerzo monetario por parte de las familias para acceder a la casa propia.

Con la intención de continuar en las líneas de esta investigación, consideramos que este tipo de reflexiones permiten poner en diálogo las formas contradictorias intrínsecas a la urbanización en el contexto capitalista, y son necesarias para pensar en ciudades más inclusivas.

Palabras clave: Urbanización en Argentina - Neodesarrollismo - Mercado de suelo - Política urbana - Acceso a la ciudad.

\section{Summary}

After the 2001 crisis, Argentina experimented a strong economical recovery that was not reflected in the conditions of city access, in a context where the real estate market has been transformed in a privileged destination of the financial investment. The main aim of this work is to characterize the actual period of Argentinian urban historicity - the neodevelopment - connected and in relationship with the neoliberal.

Methodogically this relationship was treated through the analysis of three problematic items: the land market, the urban politics and the access to the city. To do all this, it was necessary to use

\footnotetext{
${ }^{1}$ Doctoranda en Geografía en la UNLP. Miembro de equipo de investigación "Ciudad, mercado inmobiliario y conflicto. Una aproximación metodológica para la construcción de un observatorio urbano", del Centro de Investigaciones Geográficas- IDHICS, Facultad de Humanidades y Ciencias de la Educación, Universidad Nacional de La Plata. E-mail: carocisterna@gmail.com

2 Doctoranda en Estudios Urbanos en la Universidad Nacioanl de General Sarmiento. E-mail: luchamate@gmail.com
} 
secondary information from different sources, such as the National Population Census, Homes and Housing (2001 and 2010), different real state reports and web pages from state agencies among others, and then, a qualitative data analysis was done.

According to the data analysis, we can identify that during the neodevelopment there is a deepening antagonism between commercialization and city access. While the number of homes produced increased, the tenancy, overcrowding, irregular, and informal occupations increased too. The real estate market has expanded to historical levels its production and, consequently, the price of the land and of the real estate increased exponentially its value, which meant a greater economical effort for the families to be able to buy their own house.

Willing to continue with these investigation lines, we consider that these type of reflections let us dialogue about the intrinsic contradictory ways of urbanization in the capitalist context, and they are necessary to think about more inclusive cities.

Keywords: Urbanization in Argentina - Neodevelopment - Land market - Urban politics - Access to the city. 


\section{INTRODUCCIÓN}

Luego de la crisis del año 2001 la Argentina experimentó, con la salida de la convertibilidad y la devaluación del peso, una fuerte recuperación económica producto de la implementación de políticas económicas que mejoraron la rentabilidad de algunas ramas industriales y sectores exportadores. Esto a su vez se tradujo en un crecimiento de la economía a altas tasas hasta 2009, que llevó a una disminución considerable de los índices de desempleo y de pobreza. Sin embargo, el acceso a la ciudad parece ser crecientemente desigual. El mercado inmobiliario en las grandes ciudades de nuestro país se ha transformado en un destino privilegiado de la inversión financiera, lo que lleva a que el suelo urbano sufra un proceso de apreciación diferencial y que, en consecuencia, sea cada vez mayor el esfuerzo que los trabajadores deben realizar para acceder a un inmueble dentro del mercado formal.

Este trabajo se inscribe en el marco del proyecto de investigación "Ciudad, mercado inmobiliario y conflicto. Una aproximación metodológica para la construcción de un observatorio urbano" (UNLP). El mismo tiene por objetivo analizar la evolución del mercado inmobiliario del Gran La Plata en la última década y los vínculos existentes entre su desempeño y el surgimiento de conflictos urbanos que interpelan al Estado. Frente a este marco, uno de los ejes de análisis refiere a la relación entre las dinámicas macroeconómicas y la producción de ciudad, entre capital y estructura urbana. En este sentido, el presente trabajo tiene como objetivo analizar las características que asume el proceso de urbanización en la Argentina posneoliberal (2003-2015), atendiendo a tres nudos problemáticos: el mercado de suelo urbano, la política urbana y el acceso a la ciudad de las mayorías populares.

A modo de hipótesis se cree que si bien con posterioridad a la crisis de 2001 ha habido un relativo cambio en el rol del Estado frente a la política habitacional y han mejorado ciertos indicadores que reflejan el déficit habitacional, las condiciones de desigualdad en el acceso a la ciudad se mantienen e incluso se profundizan, debido a una mercantilización cada vez mayor del suelo urbano. La política habitacional, a pesar de su mayor impronta que en décadas anteriores, se constituye más en una estrategia económica de dinamización de la economía, que en una herramienta que permita resolver el problema habitacional de las amplias mayorías. Entendemos esta tensión entre mercantilización e inaccesibilidad como una parte paradojal del modelo neodesarrollista. La estrategia metodológica apuesta a articular los procesos urbanos y el neodesarrollismo en la Argentina; para ello se ha realizada una lectura sistemática de diferentes 
autores que nos permiten pensar tal relación y se ha trabajado información secundaria proveniente de diversas fuentes (censos nacionales, informes económicos oficiales, reportes inmobiliarios, etc.).

El trabajo se encuentra dividido en dos grandes partes: en la primera, en un primer momento, se hace un breve recorrido por los antecedentes teóricos para analizar un proceso de urbanización situado histórica y geográficamente, y, en un segundo momento, se abordan las continuidades y rupturas en términos macroeconómicos y políticos, entre el modo de acumulación neoliberal y el posneoliberal. En la segunda parte interesa indagar las características principales de dicho pasaje pero en términos del proceso de urbanización. Para ello, primero se describen las tres dimensiones que se propusieron analizar -el mercado de suelo urbano, la política urbana y el acceso a la ciudad de las mayorías populares- y luego se problematiza dicho proceso de urbanización pensándolo en términos de lo que creemos que es parte de una gran paradoja; finalizando con unas breves reflexiones finales.

\section{DINÁMICAS MACROECONÓMICAS Y PROCESOS URBANOS}

El interés por las peculiaridades de los procesos de urbanización a lo largo de los ciclos de acumulación capitalista en las distintas ciudades del mundo, y la identificación de períodos caracterizados por determinadas formas urbanas, lógicas de organización y dinámicas de cambio ha sido objeto de indagación de diversos autores. Fueron particularmente Henry Lefebvre y Cristian Topalov quienes, como parte de la nueva sociología francesa, comenzaron a poner en evidencia y discusión la relación entre ciudad y capitalismo.

Lefebvre (1962, 1972, 2013 [1974]), en sus trabajos sobre lo urbano, sostiene la tesis de que cada tipo de sociedad conforma un espacio específico y postula la hipótesis del advenimiento de la urbanización completa, de la sociedad urbana. En este marco plantea, dentro de la teoría unitaria del espacio, que el espacio es un producto social, parte y extensión de la estructura tecnoeconómica de la sociedad capitalista (de las relaciones económicas sociales); dando importancia de esta manera, a la reconstrucción de la historia del espacio desde la dialéctica espacio-sociedad. Por su parte, para Topalov (1979), la ciudad constituye una forma de la socialización capitalista de las fuerzas productivas y es donde se dan las condiciones generales para la búsqueda de la plusvalía de los capitalistas. Es decir, que para el capital, el valor de uso de la ciudad se basa en el hecho de que es una fuerza productiva, porque concentra las condiciones generales de la producción, de la circulación del capital, y de la producción y reproducción de la fuerza de trabajo. 
Estas proposiciones teóricas sobre la producción del espacio y la urbanización capitalista, elaboradas a partir de la experiencia europea, contribuyen a reforzar la idea de la necesidad del estudio de la ciudad capitalista, del análisis del fenómeno urbano, desde métodos de estudio que pongan en dialogo y relación las formas contradictorias de urbanización y producción del capital. Los latinoamericanos, Santos (2009), Abramo (2006, 2009), Jaramillo (2009) y Pradilla Cobos (2013), entre otros, van a reforzar estos postulados con contribuciones atinadas para el estudio de las dinámicas urbanas contemporáneas.

Interesa resaltar de este último grupo de autores, los aportes de Pradilla Cobos (2013), quien en el marco de hacer una crítica al colonialismo intelectual vigente en América Latina con teorías de los países hegemónicos, propone retomar y profundizar el desarrollo de opciones teórico-interpretativas propias para analizar los problemas urbanos en su especificidad y su diferencia. Entendiendo que la economía es determinante en la conformación de la estructura urbana y usando la herramienta teórica marxista del desarrollo desigual y combinado, convoca a los investigadores latinoamericanos a pensar cómo desde su formación o reconfiguración en el siglo XVI, las ciudades latinoamericanas estuvieron subsumidas, formal o realmente, al proceso de acumulación originaria de capital que engendró el capitalismo desde el feudalismo y que fue continuando a lo largo de los distintos patrones de acumulación: expoliación colonial hasta las independencias, capitalismo mercantil en el siglo XIX e inicios del XX (patrón primario-exportador), intervencionismo estatal de 1940 a 1980 (industrialización sustitutiva de importaciones), y neoliberal después de 1982.

Desde el reconocimiento de estos aportes, nos preguntamos a cerca del proceso de urbanización contemporáneo de las ciudades argentinas desde sus intrínsecas dinámicas económicas, políticas y sociales. Se busca analizar el vínculo entre los cambios económicos con posterioridad a la crisis de 2001, y las dinámicas urbanas de producción y acceso a las principales ciudades argentinas, buscando reforzar un estudio del proceso de urbanización situado histórica y geográficamente.

\section{DOS MODELOS DE ACUMULACIÓN: NEOLIBERALISMO Y NEODESARROLLISMO. UNA LECTURA DESDE SUS RUPTURAS Y CONTINUIDADES}

Luego de la crisis de inicio de la década, particularmente desde 2003, Argentina comenzó un proceso de: 
Normalización política e institucional y de establecimiento de las bases de un nuevo 'modelo económico' con orientación exportadora, (...) acompañado además por la constitución de una hegemonía desarrollista, impulsada por el nuevo bloque en el poder. (LÓPEZ Y DUCID; 2015).

Al igual que en todo proceso histórico, el inicio y consolidación de este nuevo modelo se asienta sobre las bases del modelo anterior, por ello, es importante describir, al menos brevemente, las características fundamentales del proyecto neoliberal y qué factores llevaron a su crisis y al surgimiento de uno nuevo.

Según Féliz y López (2012), el neoliberalismo se inició a mediados de los años setenta como un proyecto político y económico que buscaba la reconstrucción global del poder de los sectores dominantes del capitalismo, a partir del debilitamiento del conjunto de las organizaciones populares y obreras que en aquel momento ponían en cuestión dicha dominación. El neoliberalismo surge en un contexto de crisis del modelo económico de posguerra, caracterizado por cierta inclusión social; y se orientó a facilitar la reestructuración del capital a escala mundial promoviendo el desarrollo del capital financiero, la flexibilización laboral, la apertura y desregulación económica y el ajuste en el sector público, incluyendo la privatización de empresas públicas como medio para garantizar y orientar este proceso. Basualdo (2003) explica que durante el período neoliberal, la economía argentina se caracterizó por el estancamiento con fuertes oscilaciones de incremento y caída del PBI, caída de la inversión, deterioro del mercado de trabajo y de los salarios, con una consecuente concentración del ingreso, al mismo tiempo que se observó una expansión del sector financiero, proceso íntimamente vinculado al endeudamiento externo. Durante la última parte de este periodo, a partir de 1991, se estableció el régimen de convertibilidad que generó una dinámica económica con eje en la paridad cambiaria, la valorización financiera, el endeudamiento y la transferencia de recursos al exterior. Asimismo, se implementaron reformas estructurales a través de la privatización de empresas estatales, la concesión de servicios públicos, la apertura externa, la desregulación de la economía y la reforma del Estado. Esta combinación de un tipo de cambio fijo y reformas estructurales posibilitó a los sectores dominantes una expansión de sus intereses en un marco de estabilización de precios.

Las reformas políticas, económicas y sociales que se dieron en Argentina redefinieron la interrelación entre Estado, mercado y trabajo. Este modelo de desarrollo dio lugar a la profundización de la reprimarización y desindustrialización de la economía, a la centralidad del capital financiero, al ajuste del sector público, la precarización de los trabajadores y el empobrecimiento general de la población. Se consolidó un modelo de país capitalista, periférico y 
dependiente, bajo la orientación de los sectores más concentrados del capital local trasnacionalizado (FELIZ, 2011, SVAMPA, 2005; LÓPEZ, 2015, PIVA, 2015).

Desde 1998 las elevadas tasas de crecimiento económico, inversión y tasas de rentabilidad en alza, se transformaron en un proceso de desaceleración violenta, luego contracción y finalmente, en 2001, depresión profunda. La crisis de 2001 fue una crisis orgánica (LÓPEZ, 2015) que se presentó:

Como ruptura del bloque histórico neoliberal que incluía a la clase dominantes en su conjunto -conducida por los sectores trasnacionales concentrados-, a las fuerzas políticas del poder -primero el menemismo y luego, con igual perfil, la Alianza- y ciertos sindicatos y organizaciones de los subalternos. (p. 83).

Luego de la crisis, era necesario para las clases dominantes restablecer el orden social e iniciar el proceso de recomposición de su hegemonía. Así entre 2002 y 2003 se dieron una serie de cambios económicos y políticos que garantizaron la transformación en el modo de desarrollo capitalista, sin que esto signifique una transformación esencial en el mismo. Desde el repaso bibliográfico y el reconocimiento y análisis de los discursos de diversos actores dominantes y subalternos, se identifica seis políticas macroeconómicas relevantes para el período estudiado (Ibíd. 2014): el tipo de cambio real competitivo y estable (TCRCE) ${ }^{3}$, una política monetaria que favorece bajas tasas de interés reales, una política fiscal que apunta a sostener el superávit de las cuentas públicas, una política laboral ligada a la reactivación de las negociaciones colectivas y una política de ingresos compensatoria.

De esta manera, el establecimiento de un "dólar alto" -y una baja tasa de interés- creó las condiciones para una recuperación de los sectores productivos orientados al mercado interno y una mejora de competitividad para los sectores exportadores, iniciándose así una etapa en la que se registran incrementos en la actividad económica, el empleo, la recaudación impositiva, el consumo y el comercio exterior, y disminuyen consecuentemente la desocupación y la pobreza. E nuevo orden económico y político que comienza a desarrollarse a partir de las contradicciones generadas por la consolidación y crisis del neoliberalismo argentino y la salida de la convertibilidad será la superación dialéctica de dicho proceso, su conclusión lógica, y tomará la forma de un

\footnotetext{
${ }^{3}$ En enero de 2002, se decidió devaluar en más del 200\% el peso argentino -el cual se mantenía bajo una relación cambiaria fija e igualitaria con el dólar estadounidense desde la aplicación de la Ley de Convertibilidad en 1991-, estableciendo un dólar estable y caro, o el denominado "tipo de cambio real competitivo y estable". López y Ducid (2015) y Cantamutto (2012) coinciden en que la devaluación fue una estrategia político-económica de ciertos sectores concentrados de la clase dominante, en particular, de aquellos nucleados en el llamado Grupo Productivo (GP).
} 
proyecto de desarrollo capitalista neodesarrollista (FELIZ, 2011). Si bien este nuevo proyecto se caracterizó por ciertas rupturas con el modelo neoliberal precedente, no marcó transformaciones radicales de los elementos súper-estructurales heredados del patrón de acumulación anterior; así el pasaje del neoliberalismo al neodesarrollismo debe ser analizado como una transformación en la forma del desarrollo capitalista, pero que no involucró una transformación esencial en el mismo (FELIZ, 2011; LÓPEZ, 2015; PIVA, 2015).

Haciendo un análisis de los cambios a nivel de la forma del Estado, Piva (2015) sostiene la hipótesis de que el gobierno nacional kirchnerista tuvo un papel singular en la recomposición del poder político luego de la crisis de la convertibilidad. Específicamente, dicha tarea se logró a través de una estrategia de satisfacción gradual de ciertas demandas obreras y populares en los límites de un proceso de recomposición de la acumulación y de la dominación sin que existan reversiones radicales de la reestructuración del capital y del Estado de los noventa. A su vez, la recomposición del consenso por parte del Estado se dio mediante la incorporación de demandas sociales y mediante la recuperación de una mayor capacidad de arbitraje entre fracciones del capital. En este sentido, para el autor desde 2002-2003 asistimos a un proceso de desorganización de la forma de Estado existente en los años noventa, pero donde los aspectos o tendencias al cambio entran en creciente contradicción con importantes continuidades, y donde varias de estas tendencias "novedosas" han fracasado con sus objetivos o generado desequilibrios en otras áreas de la política pública.

En lo que refiere a lo económico, a partir de este nuevo modelo, los sectores dominantes vinculados al capital extranjero, que habían consolidado y aumentado su poder con el neoliberalismo, consiguieron recuperar la iniciativa y capacidad de articulación y conducción estratégica del capitalismo en Argentina. El nuevo proyecto trajo cambios en las formas y tipo de producción, como así también en la apropiación de la riqueza y su distribución. En este sentido, López (2014) destaca cómo la devaluación permitió la conformación de un bloque de diferentes actores de clase, un proyecto hegemónico, que se dio en llamar Grupo Productivo, impulsado por la Unión Industrial Argentina, el cual logró instalar una estrategia de acumulación que "...difería del ideario desarrollista clásico de los años '50 y '60: la orientación exportadora que debía tener el nuevo "modelo de crecimiento". " (p.4). Para el autor, el camino por una estrategia de acumulación ligada al desarrollo del mercado interno era resignado al enfrentarse a “...dos barreras estructurales: las actividades más dinámicas se encontraban ligadas a la exportación; y los ingresos de las clases subalternas se hallaban pauperizados" (p.5). 
De esta manera, la centralidad en el crecimiento exportador potenció el crecimiento y competitividad de la industria local en los mercados internacionales. Así, la primarización y extranjerización de la economía, comprendió el desarrollo de ramas de producción centradas en la extracción de recursos naturales por empresas privadas y capitales transnacionales, y en la superexplotación de la fuerza de trabajo. Sin embargo, partir del año 2008 se frenó el crecimiento, desapareció el superávit fiscal y se detuvo la creación de empleo, sumado al proceso de devaluación del tipo de cambio, a la suba en la tasas de interés y a una progresiva aceleración de la inflación, por lo que el modelo comenzó a mostrar sus barreras estructurales más fuertemente.

Estos aspectos económicos y políticos mediante los cuales intentamos caracterizar de forma breve el modelo de acumulación surgido con posterioridad a la crisis de 2001 resultan importantes para dar cumplimiento al objetivo de la ponencia. Por ello, serán retomados en los siguientes apartados, pero haciendo hincapié en las cuestiones que tienen que ver con la producción de las ciudades argentinas en los últimos años.

\section{EL NEODESARROLLISMO Y SU DINÁMICA EN LOS PRINCIPALES ESPACIOS URBANOS ARGENTINOS}

Habiendo caracterizado en términos macroeconómicos y políticos el pasaje del modelo neoliberal al neodesarrollista en función de ciertas rupturas y continuidades, en este apartado nos proponemos relacionar dichos cambios con el proceso de urbanización específicamente. La expansión de la mayoría de las ciudades argentinas en la última década, estuvo marcada por ciertas dinámicas políticas, económicas y sociales que podrían definir un nuevo patrón de producción del espacio urbano. Para afrontar tal interrogante resulta indispensable abordar los cambios referidos a las lógicas económicas urbanas y la política urbana, poniendo en cuestión y problematizando las condiciones de acceso a la ciudad.

\section{El Neodesarrollismo y el boom inmobiliario}

En primer lugar es necesario destacar que aunque en los inicios del nuevo régimen se dio una caída y una casi desaparición del crédito bancario hipotecario (elemento central en las dinámicas de la demanda de inmuebles), la crisis y las nuevas medidas generaron una activación histórica del mercado inmobiliario. Según del Rio (2014):

El sector de la construcción se transformó en una herramienta estratégica para 'apalancar' el crecimiento del PBI (dado el impacto del sector en la 
ampliación de la producción, el empleo y el mercado interno), creciente al doble que el conjunto de la economía y más que ninguna otra actividad económica (DNPM, 2010).

Esta apuesta al "poder de los ladrillos" se explica principalmente por el efecto multiplicador de la actividad de la construcción sobre la economía en general tras su capacidad de tracción de cadenas productivas de bienes y servicios; sumado a esto, el autor añade la importante que el tándem construcción-obra pública de la agenda pública buscó reforzar, mediante la inversión pública en infraestructura, la productividad general del sector. Complementariamente, Lapelle, López Asensio y Woelflin (2011) en su trabajo sostienen que si bien el sector inmobiliario, y de la construcción en particular, se había visto duramente afectado a fines del período de la convertibilidad, se convirtió en uno de los sectores líderes de la recuperación económica a partir de la devaluación del peso en 2002.

Diversos trabajos han definido una serie de factores que explican tal reactivación reconociendo: una alta rentabilidad por reducción de los costos de construcción debido a la devaluación ${ }^{4}$, sumado al crecimiento de los excedentes del sector agropecuario y su aparente redireccionamiento en la compra de inmuebles como activos financieros; la alta rentabilidad comparada que la inversión en suelo arrojó; las propias oscilaciones ascendentes en los precios del suelo (que potenció la especulación del mismo) y la emergencia de nuevos agentes económicos urbanos (promotores inmobiliarios) como propulsores claves de la misma dinámica de expansión (BAER, 2011; SOCOLOFF, 2013; GUEVARA, 2014; DEL RIO, LANGARD Y ARTURI, 2014; CISTERNA, MATTEUCCI Y LABORDE, 2014).

Sobre estos aspectos interesa especificar particularmente como una tasa de interés negativa frente a la inflación y a la escasez de alternativas de inversión generó una reducción de los costos de oportunidad al momento de elegir el suelo como opción (los depósitos en plazo fijo dejaron de ser una opción rentable, posibilitando que la apuesta por el $\mathrm{m}^{2}$ sea el mecanismo privilegiado de refugio de valor entre 2001 y 2010). Así Pertierra Cánepa y Pantanetti (2011), ponen al descubierto que luego de la inversión en oro, el m2 pasó a ser la inversión más rentable entre 2001 y 2010; mientras que el plazo fijo tuvo una variación en pesos de 164\%, la variación del dólar fue 296\%, la inflación acumulada ascendió al 454\%, el incremento del precio promedio del m2 fue del 502\% y el oro aumentó en 1613\%.

\footnotetext{
${ }^{4}$ El costo de la construcción se desbarrancó en 2002 seis meses más de un 50\% (Baer, 2008); pero el costo de mano de obra y de los materiales de construcción mantuvo en 2002 el mismo valor en pesos que había tenido antes de la devaluación; dando posibilidades a los agentes inmobiliarios de obtener una sobreganancia extraordinaria.
} 
En el Gráfico 1 se observa cómo durante el período 1993-2001, el Indicador Sintético de la Actividad de la Construcción (ISAC ${ }^{5}$ registró valores promedios constantes, con un leve descenso durante 1995 (que se puede entender como consecuencia de la crisis internacional), y un pico de la actividad en 1998. Durante los primeros años de la década de 2000, se produjo una gran contracción de la actividad inmobiliaria y de la construcción, producto de la coyuntura políticoeconómica (la incertidumbre financiera, devaluación del peso, falta de crédito hipotecario y financiamiento al sector). Sin embargó, será luego de 2003 que comenzará una nueva fase expansiva de la actividad constructiva hasta 2009, superando ampliamente los valores de la década anterior. En 2009 la crisis financiera internacional impuso una contracción a la industria con una caída del 2\%, siendo el crecimiento anual promedio del sector en el período 2003-2011 del 13,6\%. Movimientos similares al ISAC se pueden ver en relación a los $\mathrm{m}^{2}$ permisados para la construcción (ver Gráfico 2).

Gráfico 1: Indicador Sintético de la Actividad de la Construcción. Serie trimestral, período 1993 a 2013(Índice Base 2004 = 100).

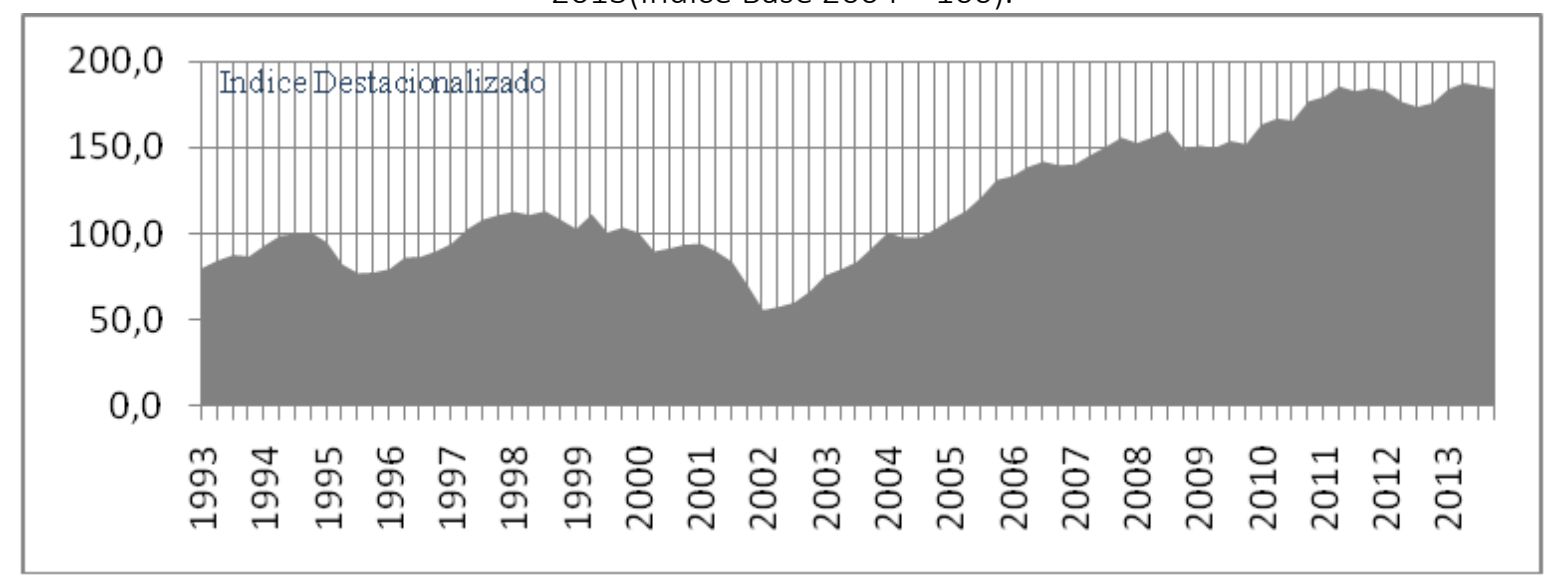

Fuente: INDEC

\footnotetext{
${ }^{5}$ El Indicador Sintético de la Actividad de la Construcción (ISAC) refleja la evolución del sector de la construcción a partir del comportamiento de un conjunto de insumos representativos: cemento, hierro redondo para hormigón, revestimientos cerámicos, pinturas para construcción y uso doméstico, vidrio plano, ladrillos huecos, asfalto y tubos de acero sin costura. Tiene periodicidad mensual y refleja la actividad de la construcción tanto en el sector público como privado.
} 
Gráfico 2: Superficie permisada total, por año en Argentina, en millones de m2. Fuente: INDEC (muestra 42 municipios) 1991- 2011.

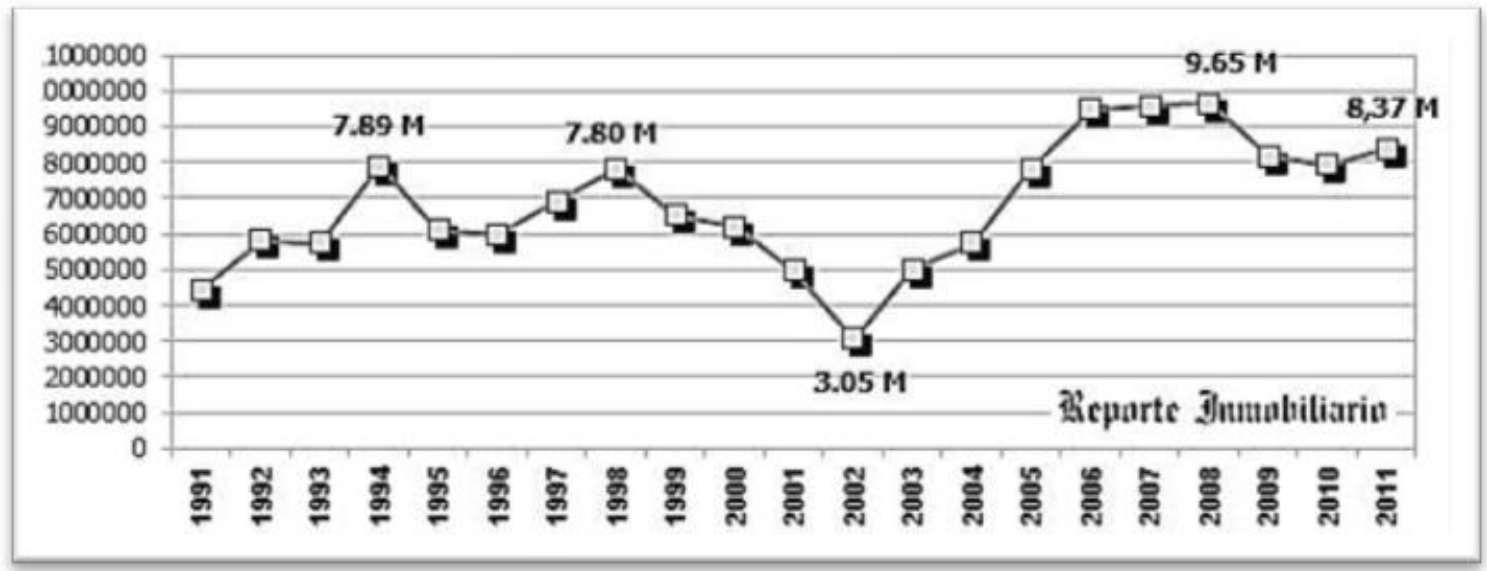

Fuente: Reporte Inmobiliario

Esta producción estuvo motorizada principalmente por viviendas de categoría alta, orientada a los sectores medio-altos y altos, que no suelen recurrir al crédito hipotecario como mecanismo de acceso, sino de su capacidad de ahorro (GUEVARA, 2014). Así, luego de la crisis de 2001, las principales ciudades del país reforzaron una funcionalidad urbana clave para el capital: absorber excedentes y reproducirlos mediante la especulación en la compra y venta de suelo urbano. De esta manera, y tal como afirma Abramo (2009), el mercado inmobiliario se convirtió en el principal eslabón de la valorización del capital y está en el corazón del proceso de generación y distribución de la riqueza urbana en las grandes ciudades latinoamericanas.

\section{La política urbana en la década de la in (ex) clusión social}

Como se planteó, la crisis del 2001 y el cambio del régimen de acumulación supusieron un cambio en el modelo de Estado, y consecuentemente en el tipo de política urbana con respecto al período neoliberal. En este punto se pretende hacer una breve caracterización de la política urbana durante la última década, sin perder de vista las rupturas y continuidades con el modelo precedente, y poniendo el acento fundamentalmente en lo que respecta a política de vivienda, por considerarla como un eje central en el acceso a la ciudad, pero sin desconocer otros aspectos importantes de dicho acceso como la infraestructura ${ }^{6}$, los servicios urbanos ${ }^{7}$ y los marcos

\footnotetext{
${ }^{6}$ Kessler (2014) desarrolla una interesante reconstrucción de antecedentes sobre el tema.

${ }^{7}$ En materia de servicios públicos se destaca una expansión de los subsidios y una reestatización de algunas empresas vinculadas. En el caso de la política de subsidios a los servicios públicos se intentó con la misma controlar la inflación y competitividad realizando un esquema en el que las tarifas eran controladas o se mantenían igual; recién en 2012 los subsidios a los sectores medios-altos y altos fue puesto en debate y
} 
regulatorios $^{8}$ de producción del espacio urbano. En este marco, resulta interesante pensar y problematizar el rol de la política urbana en esta última década a partir de las ideas de inclusión/exclusión e igualdad/desigualdad social, como sostiene Kessler (2014), son parte del espíritu de estos tiempos y presentarse tanto en la fundamentación de numerosas políticas públicas, como en las reivindicaciones de diferentes grupos y movimientos sociales.

Un eje fundamental que hace a la política urbana frente a la in/exclusión de las mayorías populares a la ciudad es lo referido al financiamiento de la vivienda, ya sea mediante subsidiospara los de menores ingresos-, o mediante el crédito -para los de ingresos medios, medio-bajos-.

Siguiendo las reflexiones de del Río (2011), durante los noventa se verifica un proceso de abandono del concepto de vivienda social ${ }^{9}$, ya que el origen del financiamiento pierde el vínculo con la solidaridad social que originalmente tenía, y se priorizan formas de cofinanciamiento y la capacidad de pago. Así, como señala Cuenya (2005), durante dicha década la política de vivienda atraviesa una redefinición ideológica y política en torno al papel que deben asumir los distintos

comenzaron a ser parcialmente sustituidos. En cuanto a la reestatización de la prestación de servicios el caso de la empresa Aguas y Saneamientos (AySA), ex Obras Sanitarias de la Nación que había sido privatizada en 1993, vuelve a quedar en manos del Estado en 2006, y adquiere como propósito la universalización del servicio. Sin embargo estos avances al no estar dentro de un proyecto político que cuestione y accione frente a las lógicas especulativas de producción urbana, termina transfiriendo recursos públicos a sectores rentitas como el sector inmobiliario que ha podido externalizar en el Estado los costos del proceso de urbanización-.

${ }^{8}$ La intervención estatal en lo que refiere a marcos regulatorios de los mercados de suelo ha continuado con la inercia liberal. Si bien existen hoy muchos debates en lo que concierne a la capacidad que tienen los gobiernos para poder establecer medidas y políticas reguladoras, poco se ha desarrollado al respecto; y cuando se han visto políticas progresistas en estos temas, muchas veces se han convertido en instrumentos funcionales a los mercados especulativos. En este sentido, podemos decir que no se ha puesto en discusión la visión patrimonialista del suelo ni del uso monopólico que los capitales inmobiliarios realizan de él, dejando de lado cuestionamientos a la apropiación privada de rentas urbanas. La reforma del Código Civil y Comercial de octubre de 2014. Continúa y profundiza el privilegio al negocio inmobiliario al otorgar, por ejemplo, legalidad a la existencia de calle privada al interior de los barrios cerrados, sacándolos a su vez de la ilegalidad (Art. 2073 al 2086. Título VII De los Conjuntos Habitacionales). En este sentido Fernández Wagner (2014) plantea que "Primó una interpretación de la ciudad que centra el foco en el lote privado, y en los intereses individuales de los propietarios, quedando débil la importancia de la acción del poder público en el desarrollo urbano, basada en restricciones administrativas al ejercicio de la propiedad inmobiliaria, que puedan trascender el paradigma liberal."

${ }^{9}$ Como plantean Cravino, Fernández Wagner y Varela (2002), a principios del siglo XX comenzaron a esbozares una serie de elementos que luego conformarían un sistema centralizado de vivienda, en torno a un esquema de seguridad social. En la década del '70, este conjunto de antecedentes converge para dar lugar a la conformación de un sistema centralizado de provisión de "vivienda social", cristalizado en el Fondo Nacional de la Vivienda (FONAVI), a cargo del Ministerio de Bienestar Social, asistido por la Subsecretaría de Vivienda, los representantes gremiales de la Confederación General de Trabajo (CGT) y la Cámara Argentina de la Construcción (CAC). Sin embargo, desde su creación, el Fondo se transforma en un campo de disputa por el control y la asignación de recursos. Uno de los principales dilemas radicó en definir si los fondos serían destinados a sostener el sistema de financiamiento privado preexistente (subsidio a la demanda) o si se buscaría reforzar el esquema de acción directa (subsidio a la oferta). Para ampliar ver del Río (2011). 
actores estatales, privados y comunitarios en la satisfacción de las necesidades de hábitat: se da un desplazamiento desde la "regulación" de la oferta (asociada a la producción estatal) hacia el financiamiento de la demanda individual; recurriendo a la emisión de títulos para generar nuevos recursos.

Al mismo tiempo, se descentraliza la política habitacional y las jurisdicciones provinciales ganan mayor protagonismo. Siguiendo el planteo de Cravino, Fernández Wagner y Varela (2002), el proceso de reforma del Estado desarticuló un sistema centralizado de provisión de vivienda social basada, al menos en su concepción, en un carácter solidario o redistributivo y "universal". Esta propuesta fue reemplazada por una política concebida desde una estrategia de focalización y descentralización, donde el Estado se retiró como vector del mercado inmobiliario para asumir un rol de facilitador y de asistencia particularizada a determinados sectores de la población, siendo las máximas del modelo: la modernización del sector por medio de la mayor participación de los promotores privados y el desarrollo del derecho de propiedad; la descentralización y la simplificación administrativa; la reducción de costos indirectos y de subsidios; la implementación de nuevos esquemas de recuperación; el abandono de la concepción de constituir reservas territoriales; y, la asimilación de un esquema de provisión de suelo (a cargo del promotor mediante la compra directa en el mercado).

Estas tendencias en la política de vivienda fueron acompañadas por decisiones más amplias en materia habitacional: la privatización de las empresas de servicios públicos, la reconfiguración de las redes de transporte, la retracción del espacio público, la venta de bienes del Estado (entre ellos reservas de tierra fiscal), junto con el desmantelamiento de otras instituciones que en ciertos aspectos habían mostrado una vocación de seguridad social. Estos cambios contribuyeron al encarecimiento de la ciudad, siendo ineludible el deterioro del hábitat de los sectores de bajos ingresos, que viendo restringidas sus posibilidad habitacionales, continuaron tomado tierra y ampliando el mercado inmobiliario informal (DEL RíO, 2011).

Ya desde fines de la década del '90, las circunstancias de la crisis político-económica que termina de "estallar" en 2001, se hacen sentir también en la política de vivienda, que queda inscripta en un contexto de reducción del gasto social y cuyos recursos pasan a estar pesificados a partir de la devaluación. Como se mencionó anteriormente, la transferencia de recursos al FONAVI mostró una tendencia decreciente a medida que avanzaba la década del noventa hastas desaparecer en 2002 con la paralización total de los planes de vivienda. A su vez, es necesario tener en cuenta que además de dicho desfinanciamiento, las necesidades aumentaron dada la 
transformación del mercado laboral y la ampliación de los sectores con graves dificultades para afrontar el acceso al suelo y a la vivienda.

En este sentido, la forma en la que reaparece la cuestión de la vivienda en la agenda pública, se encuentre mediada por el contexto de la crisis donde se entrecruzan:

La lógica de la asistencia a la emergencia, el reconocimiento de diversas organizaciones sociales que ganaron legitimidad política y la necesidad reemplazar los planes sociales por la generación de empleo genuino (DEL Río, 2011: 108-109).

Posteriormente, en lo que podría considerarse una segunda etapa, la política de vivienda recibe una inversión importante de recursos que se inscribe en una estrategia más amplia del gobierno nacional de apuntalamiento de la economía mediante la generación de empleo y reconstrucción del tejido productivo: el sector habitacional fue considerado un medio que permitía, simultáneamente, atender la emergencia habitacional, crear empleo, reactivar la economía y aplacar el conflicto social.

A partir de 2003, el superávit fiscal y la restitución de las retenciones a las exportaciones, permitieron redireccionar recursos provenientes de los beneficiados con el nuevo tipo de cambio hacia otros sectores, lo que le permitió al sector público desarrollar algunas líneas de intervención propias, sin tener que recurrir al financiamiento externo. En este contexto, la decisión del gobierno nacional fue transferir importantes recursos no reembolsables a las provincias para activar el sistema de provisión pública de vivienda y recomponer el deterioro de la base financiera del Sistema Federal de Viviendas. A partir de la creación del Ministerio de Planificación Federal, Inversión Pública y Servicios (MPFIPS), se reunieron bajo la órbita de la Subsecretaría de Desarrollo Urbano y Vivienda (SDUV) un conjunto de programas habitacionales que anteriormente estaban dispersos en distintas reparticiones nacionales y de este modo, el gobierno nacional logró garantizar el control de la política de vivienda, al igual que la etapa previa a la descentralización del FONAVI. A su vez, la cartera de vivienda pasó a depender de la Secretaría de Obras Públicas demarcando en parte la inscripción que asumiría la política de vivienda a partir de ese momento.

A continuación, en el Cuadro 1 puede verse en detalle la cantidad de viviendas realizada por cada programa desde el año 2003 a marzo de este año. Es posible observar que el mayor volumen de viviendas corresponde al Plan Federal de Construcción de Viviendas (PFCV) y FONAVI I y II, cuyo foco central es la construcción de viviendas nuevas, sumando más de 500 mil. 


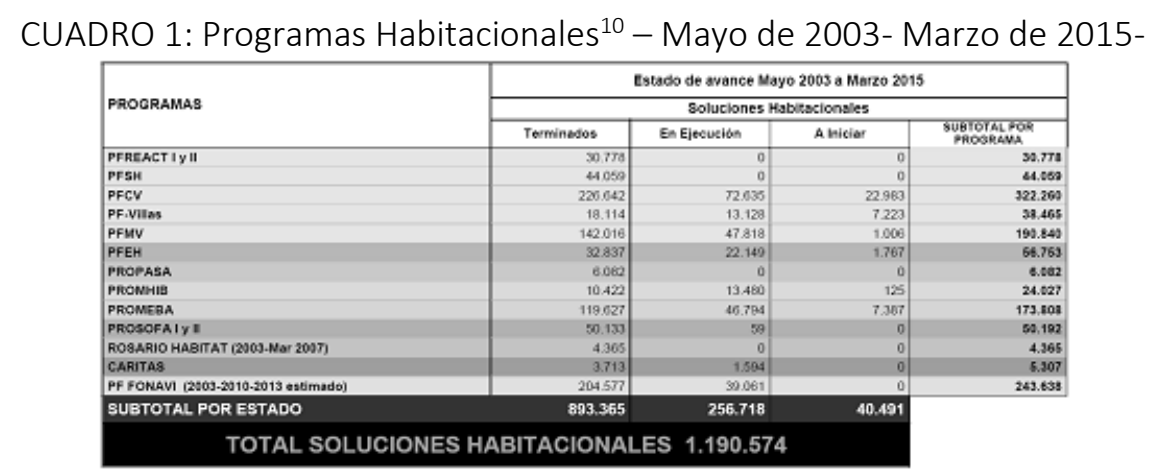

Fuente: Subsecretaria de desarrollo urbano y vivienda

La construcción de vivienda social durante el neodesarrollismo juega un papel fundamental en la economía. A pesar del variado repertorio de acción pública en materia habitacional, uno de los rasgos de la política actual es la prioridad dada a la construcción directa de vivienda nueva, a través de empresas constructoras, lo cual es sumamente coherente con la estrategia de dinamizar la economía, incentivar la industria de la construcción y generar empleo. Las características que ha adquirido la política de vivienda, como una herramienta macroeconómica estratégica, se vinculan con un cambio de contexto sociopolítico y en el rol del Estado el cual "asume un nuevo protagonismo en el marco de un proceso de reconstitución de su legitimidad, recupera ciertas facultades de intervención en la economía y asimila la idea keynesiana para a cual la inversión pública opera como un mecanismo estratégico de movilización de factores productivos" (DEL Río, 2011: 112).

Si bien la política se apoya parcialmente en Institutos Provinciales de Vivienda- nucleados en el Consejo Federal de la Vivienda- este plan de construcción masiva, diseñado y ejecutado desde el gobierno nacional, se adecua muy poco a los problemas locales. Y está aún lejos de resolver el problema habitacional, ya que según Fernández Wagner (2014), a pesar de la importante inversión pública en construcción de viviendas, no solo no se "soluciona" el problema, sino que -sobre todo en forma indirecta- con la extensión de redes, pavimentos y equipamientos sociales, al no articularse en relación a otros instrumentos de política fiscal y urbana, se contribuye a agravarlo.

\footnotetext{
10 PREACT I Y II: Programa Federal de Reactivación de Obras del FONAVI I y II / PFSH: Programa Federal de Solidaridad Habitacional / PFCV: Programa Federal de Construcción de Viviendas / PF-Villas: Programa Federal de Villas y Asentamientos Precarios / PFMV: Programa Federal Mejor Vivir / PFEH: Programa Federal de Emergencia Habitacional / PROMEBA: Programa Mejoramiento de Barrios / PROPASA: Programa de Provisión de Agua Potable, Ayuda Social y Saneamiento Básico / PROSOFA I y II: Programa de Desarrollo Social en Áreas Fronterizas del NO y NE argentinos I y II / Caritas: Programa de Viviendas Cáritas / FONAVI: Fondo Nacional de la Vivienda.
} 
Por lo que este importante esfuerzo, mientras se desarrolle en términos de política sectorial (de vivienda), va a seguir dejando gran parte del problema habitacional sin abordar.

En relación al crédito hipotecario, las condiciones de acceso al mismo en la década neodesarrollista no variaron considerablemente, reconociéndose al PROCREAR como la política crediticia de mayor trascendencia. Tras la privatización en 1997 del Banco Hipotecario Nacional, no existe en Argentina ninguna entidad pública que se ocupe específicamente del crédito hipotecario (GUEVARA, 2014), y la oferta de los mismos se da desde bancos privados o públicos, pero con altas tasas y condiciones que los hacen inaccesibles a grandes estratos de la población. Sin embargo, en 2012 el gobierno nacional lanzó el Programa de Crédito Argentino (PRO.CRE.AR) ${ }^{11}$ con fondos del ANSES. EI PROCREAR se constituyó en una política de carácter progresista, una iniciativa virtuosa (DUARTE, 2013), en tanto genera nuevas condiciones de acceso y mejoramiento de la vivienda a sectores medios que antes del lanzamiento del programa no calificaban para los créditos hipotecarios existentes. Sin embargo, este programa es pensado y lanzado también como una política contracíclica, que tras una caída de la tasa de crecimiento económico en 2012 busca dinamizar el sector de la construcción.

Frente a este tipo de proceso, Fernández Wagner (2014) señala el límite de este tipo de política neo keynesiana al advertir el rol excluyente de promoción de crecimiento económico y generación de empleo formal, donde se desconoce complejos problemas socioterritoriales y se lleva a profundizar de la desigualdad socio-espacial mediante su incidencia en el aumento del precio del suelo. El neodesarrollismo nos plantea un nuevo debate, dado que se trata de una fase del desarrollo latinoamericano (posneoliberal) que centra el eje del desarrollo en el mercado interno -lo cual seguramente es más apropiado definir como "neo-keynesianismo"- pues el objetivo primordial consiste en "sostener la demanda efectiva" (como proponía J. M. Keynes). Es decir que se trata de políticas con una importante intervención estatal que buscan acelerar el crecimiento económico, por encima de las leyes del mercado.

\footnotetext{
${ }^{11}$ Se prevé la construcción de 400.000 viviendas hasta 2016. Estas están destinados a las familias argentinas que no tengan vivienda propia o que teniéndola necesiten realizar refacciones o ampliaciones de la misma, ya sea a través de la construcción de viviendas nuevas en terreno propio o a comprar, la adquisición de una vivienda construida en terrenos del Estado, o bien la refacción y/o ampliación de viviendas existentes; como a la compra de viviendas recién terminadas o próximas a terminarse por desarrolladores privados.
} 


\section{Acceso a la ciudad: el mercado se reserva el derecho de admisión}

La mencionada mercantilización del espacio urbano implicó una profundización de la disminución de las posibilidades de acceso de grandes sectores sociales a la ciudad. Durante el neoliberalismo y el neodesarrollismo, la ciudad se mercantilizó de tal modo que limitó su uso a las formas de apropiación privada de aquellos que tuvieron las condiciones económicas para hacerlo ${ }^{12}$. Tomaremos a continuación cuatro dimensiones claves que nos permiten visualizar tal proceso: el esfuerzo monetario para acceder al inmueble, la reestructuración del régimen de tenencia, indicadores de déficit habitacional y cobertura de servicios urbanos a nivel nacional.

El principal condicionante de acceso a la compra de inmuebles habitacionales es la pertenencia a un determinado estrato socioeconómico con ciertos niveles de ahorro e ingreso (YUJNOVSKY, 1974). Luego de la crisis 2001 la economía argentina experimentó una fuerte recuperación económica, que fue acompañada por un aumento importante del empleo y la disminución de la pobreza ${ }^{13}$; sin embargo la recuperación del salario no logró alcanzar la valorización de los inmuebles, por lo que la compra de los mismos se tornó una difícil meta para la gran mayoría social.

Del Rio, Langard y Arturi (2013) trabajan la relación entre el salario mínimo vital y móvil, remuneración promedio de los asalariados del sector privado, precios de inmuebles y suelo urbano para la ciudad de Buenos Aires durante el período 2001-2011'14; y constatan que partir de 2003 todas las variables tuvieron una tendencia ascendente y en 2005 los precios de los departamentos y del suelo urbano sobrepasaron los valores en dólares de 2001. Los autores ponen en evidencia que el esfuerzo monetario necesario para la compra de una vivienda es mayor, con su punto más elevado durante el 2006: mientras que en 2001 para la compra de un departamento de $100 \mathrm{~m}^{2}$ en

\footnotetext{
12 Según Cravino, Fernández Wagner y Varela (2002), la reinstauración ideológica del principio liberal de responsabilidad individual en el acceso al suelo y a la vivienda instalada durante el modelo neoliberal, es convergente con la erosión del mundo de la producción y el empleo. Los cambios en el mercado de trabajo, introducen profundas transformaciones en la situación social, los cuales sin duda se tradujeron en las condiciones de acceso al hábitat. La inestabilidad de los ingresos fue amenazando el bienestar de las familias, la incertidumbre económica alteró los niveles de consumo, la planificación de los gastos domésticos y las estrategias habitacionales; por lo que avanzado los '90, la inestabilidad ocupacional, las altas tasas de desocupación, la profundización de la informalidad laboral y el empobrecimiento de los hogares, fueron acompañados por una contracción de las oportunidades habitacionales de los sectores populares.

${ }^{13}$ La tasa de desempleo pasó a ubicarse según datos oficiales por debajo de los dos dígitos, con el valor más bajo en la década en el 2010 (7,3\%). Mientras que en 2002, la línea de pobreza superaba el 50\% de los hogares argentinos y la indigencia más de un 25\%, para 2007 la pobreza había caído al 23,4\% y la indigencia rondaba el $8 \%$.

${ }^{14}$ Para ampliar sobre este trabajo ver del Río, Langard y Arturi (2013).
} 
la Ciudad de Buenos Aires se necesitaban 9,1 años/salario, en 2006 se requirieron 18,4 años/salario y en 2011 15,6 años/salario ${ }^{15}$. Baer (2014) en su estudio sobre la Región Metropolitana de Buenos Aires, y Monayar (2014) y Gargantini et al. (2014) para la ciudad de Córdoba, constatan similares relaciones.

Un segundo aspecto que nos interesa mostrar es la reestructuración en el régimen de tenencia. En una escala nacional, según el Censo Nacional de Población, Hogares y Vivienda (2010) se verifica por primera vez desde el censo de 1947 una inflexión en la reducción de la inquilinización: mientras que en 2001 el 11,1\% de los hogares eran inquilinos de la vivienda a nivel nacional, en 2010 los hogares inquilinos pasaron a ser el 15,7\%. Asimismo, por primera vez en un período intercensal, los propietarios disminuyen $(70,6$ a 67, 7\%) en relación al número de inquilinos (11,1 a 16,4\%). Dato que resulta curioso si se tiene en cuenta que históricamente - como parte de la movilidad social ascendente de las clases medias- el número de propietarios crecía entre períodos censales, en relación a las otras formas de tenencia.

CUADRO 2: Vivienda según tipo de tenencia en Argentina. 2001 y 2010

\begin{tabular}{l|l|l|l|l|}
\hline & Año 2001 & & 2010 & \\
\hline Total de Hogares & 10.073 .625 & 100 & en \% & \\
\hline $\begin{array}{l}\text { Propietarios de la vivienda } \\
\text { y el terreno }\end{array}$ & 7.115 .508 & 70.64 & 12.171 .675 & 100 \\
\hline $\begin{array}{l}\text { Propietarios de la vivienda } \\
\text { solamente }\end{array}$ & 432.009 & 4.29 & 8.240 .293 & 67.7 \\
\hline Inquilino & 1.122 .208 & 11.14 & 533.629 & 4.43 \\
\hline Ocupante por préstamo & 329.985 & 8.24 & 1.960 .676 & 16.11 \\
\hline Otra situación & 320.236 & 3.18 & 844.694 & 6.94 \\
\hline
\end{tabular}

Fuente: Elaboración propia, en base a Censos Nacionales de Población, Hogares y Vivienda, 2001-2010 (INDEC).

Paralelamente, y ante la ausencia de un indicador estadístico de informalidad urbana, los datos del cuadro resultan útiles para aproximarnos a una lectura acerca del tal fenómeno. Leyendo conjuntamente los indicadores de "propietarios de la vivienda solamente", "ocupante por préstamo" y aquellos que se engloban en el censo como "otra situación", vemos como hay un aumento del total en términos absolutos de cerca de 140.000 hogares de tenencia irregular.

\footnotetext{
${ }^{15}$ A diferencia, de otros bienes de consumo como por ejemplo de los automóviles que si se tiene en cuenta el salario medio en la última década, la capacidad para poder comprar uno se redujo en los últimos 10 años de 30 a 15 sueldos (ACARA, 2014).
} 
En el Cuadro 3 se presentan la evolución de algunos indicadores asociados al déficit habitacional. En términos absolutos y relativos los hogares con situación deficitaria disminuyeron, como así también las viviendas precarias irrecuperables ${ }^{16}$ y en menor medida aquellas que se consideran recuperables ${ }^{17}$; sin embargo si se observan aquellos hogares sin déficit material pero con presencia de hacinamiento crítico ${ }^{18}$ sorprende el aumento de más del $43 \%$ en el período 0110. A su vez, en relación a este último indicador si se observa en detalle los hogares que comparten vivienda, si bien el porcentaje había disminuido en el período 91-01, en el último período intercensal aumenta en más del 100\%. Llaman la atención que frente a una disminución del déficit habitacional, haya un aumento del hacinamiento e incluso sean cada vez mayor la cantidad de viviendas desocupadas desde la década de los noventa, pero con mayor profundidad entre 2001 y 2010. Es decir, el último censo arrojó que el 18\% de las viviendas del país (2.494.618 viviendas) se encuentran vacías, porcentaje que en la ciudad de Buenos Aires trepa al 24\%; de este modo, no se trata solo de la necesidad de nuevas viviendas, sino de generar políticas que favorezcan el acceso a las ya existentes.

\footnotetext{
${ }^{16}$ Las viviendas precarias irrecuperables son aquellas que por sus materiales de construcción o por su naturaleza deberían ser reemplazadas por nuevas viviendas (ranchos, casillas, locales no construidos para fines habitacionales y las viviendas móviles).

${ }^{17}$ Las viviendas recuperables son aquellas que mediante obras de refacción pueden mejorar sus condiciones de habitabilidad; en ellas se incluyen inquilinato, hotel-pensión y casa Tipo B. Según el INDEC, se define como casa a la vivienda con salida directa al exterior. La casa Tipo B es aquella que cumple por lo menos una de las siguientes condiciones: no tiene provisión de agua por cañería dentro de la vivienda; no dispone de retrete con descarga de agua; tiene piso de tierra u otro material precario. El resto de las casas es considerado como casas de Tipo A.

18 Los hogares residentes en viviendas sin déficit con hacinamiento crítico corresponden a los hogares residentes en casas Tipo A o Departamento con 3 o más personas por cuarto.
} 
CUADRO 3: Distribución de hogares según situación habitacional y tasa de crecimiento intercensal y distribución de viviendas ocupadas y hogares particulares en situación de cohabitación, viviendas desocupadas y tasa de crecimiento intercensal. Total país. 1991-2001-2010

\begin{tabular}{|c|c|c|c|c|c|c|}
\hline & |1991 & |2001 & 2010 & |91-01 & |01/out & |91-10 \\
\hline Total Hogares País & $8.927 .289(100 \%)$ & $10.073 .625(100 \%)$ & $12.171 .675(100 \%)$ & $12.8 \%$ & $20.8 \%$ & 36.35 \\
\hline Hogares con situación deficitaria & SD & 2.315 .249 & 2.109 .234 & SD & $-8.9 \%$ & SD \\
\hline $\begin{array}{lcl}\text { En } & \text { viviendas } & \text { precarias } \\
\text { irrecuperables } & \\
\end{array}$ & $651.766(7.3 \%)$ & $543.037(5.4 \%)$ & $447.431(3.7 \%)$ & $-16.7 \%$ & $-17.6 \%$ & $-31.4 \%$ \\
\hline En viviendas recuperables & $1.573 .804(17.6 \%)$ & $1.646 .965(16.3 \%)$ & $1482.307(12.2 \%)$ & $4.6 \%$ & $-10.0 \%$ & $-5.8 \%$ \\
\hline $\begin{array}{l}\text { En viviendas sin déficit of hac. } \\
\text { critico }\end{array}$ & SD & $125.238(1.2 \%)$ & $179.496(1.5 \%)$ & SD & $43.3 \%$ & SD \\
\hline Hogares que comparten vivienda & 732.037 & 664.859 & 1.478 .885 & $-9.2 \%$ & $112.4 \%$ & $50.5 \%$ \\
\hline Viviendas desocupadas & 1.090 .084 & 1.546 .781 & 2.494 .618 & $41.9 \%$ & $61.3 \%$ & $56.6 \%$ \\
\hline
\end{tabular}

Fuente: del Rio (2014), en base a Censos Nacionales de Población, Hogares y Vivienda, 1991-2001-2010 (INDEC).

Por último, veremos algunos indicadores en relación a la cobertura de servicios indispensables como agua potable, servicios cloacales y gas. A partir de los datos censales de 1999, 2001 y 2010 y de un informe del Ministerio de Planificación Federal, Inversión Pública y Servicios (MPFIPYS, 2012), es posible identificar ciertos déficits en las condiciones de las viviendas y establecer comparaciones entre las distintas provincias del país.

En relación con el acceso al agua corriente, en 2010 el 83,9\% de los hogares del país contaba con ese servicio, observándose un leve mejoramiento respecto de 2001 cuando era el $80,1 \%$ pero mucho mayor si se tiene en cuenta que en 1999 era el de $66 \%$. De las once provincias por debajo del promedio nacional en 2001, cuatro lo alcanzan en 2010 pero de las siete restantes algunas seguían estando muy por debajo del promedio nacional, entre ellas Formosa, Santiago del Estero y Chaco. Por otro lado, respecto a los servicios sanitarios, para 2010 el 54,6\% de los hogares contaba con servicios cloacales, mientras que en 2001 lo hacía un $42.5 \%$ y en 1999 un 34.3\%. Al igual que en el caso anterior, en 2001 once provincias estaban por debajo del promedio nacional, pero se le suma también el conurbano bonaerense; para 2010, si bien había mejoras en términos absolutos, solo dos de esas once (San Juan y La Rioja) llegaron al promedio nacional. Por último, en relación a la cobertura de gas natural, para 2010 el 56,1\% de los hogares del país contaba con este servicio, si se lo compara con el 51,4\% en 2001.

A partir de estos datos, puede observarse un mejoramiento general de indicadores, pero con continuidad en la desigualdad profunda entre algunas provincias del país y entre la ciudad formal. Las tendencias contrapuestas se vinculan a que la misma reactivación catalizó o reforzó problemas de acceso a la vivienda: en efecto, los precios de los terrenos y los inmuebles urbanos se 
incrementaron notablemente debido a la disminución de las tierras disponibles, la mejora económica en general y a la de la industria de la construcción en particular (KESLER, 2014). Esta es una de las situaciones que consideramos paradójicas del período neodesarrollista y que nos proponemos trabajar en el apartado siguiente.

\section{LAS PARADOJAS DEL MODELO NEODESARROLLISTA FRENTE AL ACCESO A LA CIUDAD}

Tal como se planteó al inicio de este trabajo, creemos que existen ciertas tensiones entre las ideas de inclusión, distribución e igualdad, tan presentes en estos tiempos -tanto en la fundamentación de numerosas políticas públicas, como en las reivindicaciones de diferentes grupos y movimientos sociales-, y las condiciones reales de acceso a la ciudad por parte de las mayorías. Recuperando las ideas de varios autores, creemos que el neodesarrollismo surge como un nuevo modelo en el cual los sectores dominantes vinculados al capital extranjero -que habían consolidado y aumentado su poder con el neoliberalismo- consiguieron recuperar la iniciativa y capacidad de articulación y conducción estratégica del capitalismo en Argentina. Si bien este nuevo proyecto trajo cambios en las formas y tipo de producción, como así también en la apropiación de la riqueza y su distribución no ha significado verdaderos cambios estructurales en relación al modelo precedente. A su vez, como se mencionó anteriormente, la recomposición del poder político se logró a través de una estrategia de satisfacción gradual de demandas obreras y populares en los límites de un proceso de recomposición de la acumulación y de la dominación sin reversiones radicales de la reestructuración del capital y del Estado de los noventa (FÉLIZ Y LÓPEZ, 2012; LÓPEZ Y DUCID, 2015; PIVA, 2015).

En este sentido, nos preguntamos ¿Cómo se expresan estas contradicciones en clave urbana? ¿Por qué ante una producción cada vez mayor de tierra urbana y vivienda, y en el marco de un giro político donde se busca garantizar la inclusión social, el acceso a la ciudad para importantes sectores de la sociedad se ha visto restringido?

En base a los datos trabajados en esta ponencia, podemos identificar que durante el neodesarrollismo se da una profundización a nivel nacional del antagonismo entre mercantilización y acceso a la ciudad. Por un lado, se producen cada vez más viviendas (tanto desde el mercado inmobiliario como da la política habitacional estatal); pero por otro lado, aumenta el inquilinato, el hacinamiento y las ocupaciones con tenencia irregular o informal.

El mercado inmobiliario expandió a niveles históricos su producción con posterioridad a la crisis, tal como se trabajo en el apartado 4.1 con el análisis de ISAC y superficie permisada, sin 
embargo, esta producción estuvo direccionada a viviendas de alta categoría orientadas a sectores medios y medio-altos, con suficiente capacidad de ahorro y que incluso buscaron la inversión en ladrillos como forma de ahorro (el aumento de viviendas desocupadas en el período intercensal, es un posible indicador explicativo de esta situación). A su vez, esta expansión fue acompañada por una iniciativa estatal fundamentalmente vinculada a la producción de vivienda nueva, en coherencia con una política contracíclica de generación de empleo y reactivación de la economía, más que a una política habitacional que aborde el problema de modo integral.

Como corolario de esta expansión, el precio del suelo y de los inmuebles aumentó exponencialmente su valor, lo que implicó un mayor esfuerzo monetario por parte de las familiar para acceder a la casa propia. Esta restricción en el acceso ${ }^{19}$ puede visualizarse en tres situaciones ya trabajadas: el crecimiento del hacinamiento crítico, el histórico cambio en la estructura de tenencia donde se observa un aumento del inquilinato y la informalidad urbana ${ }^{20}$.

\section{CONCLUSIONES}

A lo largo del artículo hemos analizado las características que asume el proceso de urbanización en la Argentina luego de la crisis de 2001, prestando atención a lo que consideramos tres grandes nudos problemáticos presentes en dicho proceso: el mercado de suelo urbano, la política urbana y el acceso a la ciudad. A modo de cierre, pero con la intención de continuar en las líneas de esta reflexión, entendemos que, en lo que respecta a producción urbana y acceso a la ciudad, el modelo neodesarrollista se caracteriza por contener rasgos novedosos pero al mismo tiempo son contradictorios, que hacen a sus propios límites.

\footnotetext{
${ }^{19}$ Es interesante la lectura de Fernandez Wagner (2014) quien sostiene que "Lo que es crítico es que también se naturaliza el costoso impacto que tiene el aumento del precio del suelo en la profundización de la desigualdad socioespacial y por consiguiente de las penurias habitacionales de clases medias y bajas. Estas últimas, progresivamente están afectadas -en grandes centros urbanos- por una aceleración de dos procesos: el allegamiento familiar (los hijos que forman nuevos hogares se quedan habitando, y hacinándose, en la casa paterna) y las villas que hoy aumentan su tamaño -y exponencialmente su población- por el alquiler de cuartos que realizan los pobladores originales en las áreas centrales. Mientras, en la periferia, recrudecen "las tomas de tierras" motorizadas por las ventas de suelo en loteos fraudulentos".

${ }^{20}$ Los cambios en las condiciones macroeconómicas mencionados, no sólo incidieron en la potenciación de un mercado inmobiliario altamente segmentado y excluyente, sino que también llevaron a transformaciones en las estrategias de subsistencia de los sectores populares. Del Rio (2014), destaca en este marco el paso de estrategias orientadas a garantizar la alimentación en un contexto de alto desempleo y pobreza de principios de la década del 2000, hacia estrategias que tienden a la satisfacción de necesidades en otro horizonte, como el acceso a la tierra y vivienda en un contexto de disponibilidad de recursos corrientes para afrontar procesos de autoconstrucción y autourbanización.
} 
Estas tensiones mencionadas anteriormente, de alguna manera reflejan la incapacidad que aún existe para redefinir las lógicas de reproducción de las ciudades, que continúan siendo guiadas por la lógica de acumulación del capital. Entendemos, así, que en este último tiempo, han sido escasos los intentos por redefinir la política urbana en términos verdaderamente más inclusivos. Si no que por el contrario, se ha logrado instalar una intervención política de creación de vivienda que lleva a la naturalización de la lógica mercantil de la producción urbana. Consideramos que este tipo de reflexiones permiten poner en diálogo y relación las formas contradictorias intrínsecas a la urbanización en el contexto capitalista, y son necesarias para pensar en modelos de ciudad más inclusivos.

\section{BIBLIOGRAFÍA Y FUENTES CONSULTADAS}

ABRAMO, Pedro. La ciudad caleidoscópica: Una visión heterodoxa de la economía urbana. España: Netbiblo. 2006.

La producción de las ciudades Latinoamericanas: mercado inmobiliario y estructura urbana. Ecuador: OLACCHI. 2009.

ALESSANDRI CARLOS, Ana Fani. A Condição Espacial. Sao Pablo: Contexto. 2011.

BAER, Luis. Precio del suelo, actividad inmobiliaria y acceso a la vivienda. Revista Ciudad y Territorio, 1 (156), 345-360. 2008.

El mercado de suelo formal de la Ciudad de Buenos Aires en su contexto metropolitano. Tesis doctoral. Buenos Aires: FFyH-UBA. 2011.

BASUALDO, Eduardo. Las reformas estructurales y el Plan de Convertibilidad durante la década de los noventa. El auge y la crisis de la valorización financiera. Realidad Económica, 200, 44-83. 2003

CISTERNA, Carolina, MATTEUCCI, Lucía Y DONATO LABORDE, Matías. Aproximaciones teóricas al concepto de régimen urbano y su interpretación en la producción de los espacios urbanos argentinos contemporáneos. X Bienal del Coloquio de Transformaciones Territoriales. Pagina web: en proceso. Córdoba. 2014

CISTERNA, Carolina, MATTEUCCI, Lucía Y DONATO LABORDE, Matías. Macroeconomía y ciudad. El neodesarrollismo y los espacios urbanos argentinos. XV Encuentro de Geógrafos de América Latina. Libro de Congreso y CDRom: ISBN 978959716750-1. Pagina web: en proceso. La Habana. 2015.

CRAVINO, Cristina, FERNÁNDEZ WAGNER, Raúl y VARELA, Omar. Notas sobre la política habitacional en el área metropolitana de Buenos Aires en los'90. Buenos Aires: Mimeo. 2002

CUENYA, Beatriz. Cambios, logros y conflictos en la política de vivienda en la Argentina hacia fines del siglo XX. Boletín CF+S Ciudades para un Futuro más Sostenible, 29, 30. Instituto Juan de Herrera. Madrid. 2005 
DEGANO, Daniela. Del déficit habitacional a la vivienda pública ¿̇o al déficit nuevamente?. Acerca de las condiciones habitacionales de las viviendas realizadas en Argentina por políticas públicas y su sostenibilidad. Revista Arquisur, 5, 20-31. 2014

DEL RÍO, Juan Pablo. El lugar de la vivienda social en la ciudad: Un análisis de la política habitacional desde el mercado de localizaciones intra-urbanas y las trayectorias residenciales de los habitantes. Tesis doctoral. La Plata: Universidad Nacional de La Plata. 2012. Disponible en: http://www.memoria.fahce.unlp.edu.ar/tesis/te.464/te.464.pdf

Transformaciones habitacionales en la Región Metropolitana de Buenos Aires. El pasaje del neoliberalismo al neodesarrollismo urbano. Dossier La cuestión regional, Revista Geograficando, en prensa. La Plata: 2014

DEL RíO, Juan Pablo; VERTIZ, Francisco y URSINO, Sandra. Ciudad y políticas públicas. Hacia una definición de la política urbana. Actas del Congreso de Geografía de Universidades Nacionales. Mendoza. 2013

DEL RÍO, Juan Pablo, LANGARD, Federico y ARTURI, Diego. La impronta del mercado inmobiliario en el período neodesarrollista. Revista Realidad Económica, 283, 77-101. Buenos Aires. 2014

DUARTE, Juan. El Programa de Crédito Argentino del Bicentenario (Pro.Cre.Ar). Café de ciudades, 12, 133-134. Buenos Aires. 2013.

FÉLIZ, Mariano. Los limites macroeconómicos del neo-desarrollismo. Herramientas, 39. Buenos Aires. 2008.

FÉLIZ, Mariano y LÓPEZ, Emiliano. Proyecto neodesarrollista en la Argentina. ¿Modelo nacionalpopular o nueva etapa en el desarrollo capitalista?. Editorial El colectivo y Ediciones Herramienta. Buenos Aires. 2012

FERNÁNDEZ, Cristina. Palabras de la Presidenta de la Nación. Acto de anuncio de la creación de la Secretaría de Acceso al Hábitat. En: http://www.presidencia.gob.ar/. 2014

FERNÁNDEZ WAGNER, Raúl. Democracia y ciudad: procesos y políticas urbanas en las ciudades argentinas: 1983-2008. 1ed - Los Polvorines: Univ. Nacional de General Sarmiento. Buenos Aires. 2008.

Los limites de las políticas neo keynesianas en desarrollo urbano y vivienda. I Seminario Nacional Experiencias alternativas de producción socio-habitacional. Universidad de Córdoba. 2014

GARGANTINI, Daniela; MARTIARENA, Miguel; GREPPI, Veronica. y PERALTA, Joaquín. La vivienda: un derecho inaccesible en Córdoba Capital. I Seminario Nacional Experiencias alternativas de producción socio-habitacional. Universidad de Córdoba. 2014

GÓMEZ, Ricardo. Neoliberalismo Globalizado. Refutación y debacle. Ediciones Macchi. Buenos Aires. 2003

HARVEY, David. La condición de la posmodernidad: investigación sobre los orígenes del cambio cultural. Buenos Aires: Amorrortu. 2004

Espacios del capital. España: Ediciones Akal, S.A. 2007 
JARAMILLO, Samuel. Hacia una teoría de la renta del suelo urbano. Bogotá: CEDE, Universidad de Los Andes. 2009

KESSLER, Gabriel. Tendencias contrapuestas en educación, salud y vivienda. En: Kessler, G., Controversias sobre la desigualdad. Argentina, 2003-2013, 115-199. Buenos Aires: Fondo de Cultura Económica. 2014

LEFEBVRE, Henri. El derecho a la ciudad. Barcelona, Península. 1969

Espacio y política. El derecho a la ciudad, II. Barcelona, Península. 1972

La producción del espacio. (Traduccción: Martinez Lorea). Barcelona: Capitán Swing. 2013.

]LÓPEZ, Emiliano. Políticas macroeconómicas y procesos de clase en Argentina (2002-2007). Revista Realidad Económica, 288, 90-120. Buenos Aires. 2014

LÓPEZ, Emiliano y DUCID, Manuel. La emergencia de la hegemonía desarrollista: clases dominantes y estrategias político discursivas en la Argentina reciente (2002-2007). Revista Mexicana de Sociología, en prensa. 2015

MONAYAR, Virginia. Asequibilidad al suelo urbano en Córdoba. I Seminario Nacional Experiencias alternativas de producción socio-habitacional. Universidad de Córdoba. Córdoba. 2014.

MATTEUCCI, Lucía, RAMíREZ, Lucas, DEL Río, Juan Pablo y RELLI, Mariana. Construcción de datos para el análisis de los agentes inmobiliarios del Gran La Plata: aspectos metodológicos y resultados preliminares (primer semestre 2013). Actas de las XV Jornadas de Investigación del Departamento de Geografía y el Centro de Investigaciones Geográficas, FaHCE, UNLP. ISSN 2362-4221. En: http://jornadasgeografia.fahce.unlp.edu.ar/xv-jornadas/actas/06.Ramirez-L/view. 2013

PERTIERRA CÁNEPA, Francisco y PANTANETTI, Mariano. El fideicomiso y el boom inmobiliario argentino. Documento de trabajo, 451. Área Finanzas y Negocios. Universidad de CEMA. Buenos Aires. 2011

PRADILLA COBOS, Emilio. La ciudad capitalista en el patrón neoliberal de acumulación en América Latina. Seminário Internacional: A Cidade Neoliberal na América Latina: desafios teóricos e políticos, IPPUR/UFRJ. Rio de Janeiro, 2013.

RODRíGUEZ, María Carla y DI VIRGILIO, Mercedes. Caleidoscopio de las políticas territoriales. Rompecabezas para armar. Buenos Aires: Ed. Prometeo. 2011

SABATINI, Francisco. CÁCERES, Gonzalo. Relación entre promoción inmobiliaria y segregación residencial: giros insospechados de la ciudad latinoamericana. Lincoln Institute of Land Policy (Documento de trabajo). 2005

SANTOS, Milton. Por uma Economía Politica da Cidade: O caso de Sao Paulo. San Pablo: Ddusp. 2009

SVAMPA, Maristella. La sociedad excluyente. La Argentina bajo el signo del neoliberalismo. Buenos Aires: Taurus. 2005

KESSLER, Gabriel. Controversias sobre la desigualdad. Argentina 2003-2013. Buenos Aires: Fondo de Cultura Económica. 2014. 
TECCO, Claudio. La gestión del desarrollo local y la administración de bienes públicos. Sobre modelos y prácticas en la organización de la gestión municipal. Seminario Nacional de RedMuni: teoría y práctica en la gestión del desarrollo local y regional en Argentina. 2004

THEODORE, Nik, PECK, Jamie y BRENNER, Neil. Urbanismo neoliberal. La ciudad y el imperio de los mercados. Revista Temas Sociales Nº6, p.12. 2009

TOPALOV, Christian. La urbanización capitalista. México: Editorial Edicol. 1979

VIVES, Sonia. y RULLAN, Onofre. El papel de la propiedad privada del suelo en el proceso de acumulación del capital de la ciudad neoliberal en el estado español. X Coloquio y Jornadas de Campo de Geografía Urbana, Bilbao. España. 2010

YUJNOSVKY, Oscar. Revisión histórica de la política de vivienda en la Argentina desde 1880. Summa № 72. España. 1974

\section{Fuentes}

Instituto Nacional de Estadísticas y Censos. En: http://www.indec.mecon.ar/

Reporte Inmobiliario. En: http://www.reporteinmobiliario.com.ar

Subsecretaría de Desarrollo Urbano y Vivienda. En: http://www.vivienda.gob.ar/

Trabalho enviado em 30 de setembro de 2015.

Aceito em 14 de outubro de 2015. 